\title{
Foundations of cable car towers upon alpine glaciers
}

\author{
Wolfgang Fellin and Bernhard Lackinger*
}

15 September 2007

\begin{abstract}
This version of the article has been accepted for publication, after peer review and is subject to Springer Nature's AM terms of use, but is not the Version of Record and does not reflect post-acceptance improvements, or any corrections. The Version of Record is available online at: http://dx.doi.org/10.1007/ s11440-007-0042-z
\end{abstract}

This paper presents a design approach for strip footings upon glacier ice. Safety against ultimate limit state is proved by the geotechnical slip-line field solution by Prandtl. Glacier ice at $0^{\circ} \mathrm{C}$ can be modelled as purely cohesive material. Statistical evaluation of uniaxial compression tests with high strain rate revealed a mean value of the cohesion of $600 \mathrm{kPa}$ and a characteristic value $c_{k}=355 \mathrm{kPa}$ ( $5 \%$ fractile). With a coefficient of variation $V_{c}=0.3$, the partial safety factor turns out to be $\gamma_{c}=1.9$. An approximate solution for estimating the creep settlement rate $\dot{u}$ is presented, to check the serviceability limit state: $\dot{u}=\beta_{1} b^{\beta_{2}} p^{\beta_{3}}$, with the width $b$ of the strip foundation, $p$ the foundation pressure and $\beta_{1}=8.6 \times 10^{-5} \mathrm{~m} \mathrm{kPa}^{-\beta_{3}} \mathrm{a}^{-1} \mathrm{~m}^{1-\beta_{2}}, \beta_{2}=0.92$, $\beta_{3}=1.74$ for ice at $0^{\circ} \mathrm{C}$. Experiences on Stubai glacier with grate shaped

\footnotetext{
${ }^{*}$ Universität Innsbruck, Institut für Infrastruktur, Arbeitsbereich für Geotechnik und Tunnelbau, Technikerstraße 13, A-6020 Innsbruck, e-mail:wolfgang.fellin@uibk.ac.at, Tel: ++43/512/507-6672
} 
footings showed that creep settlements occurring per year due to maximum foundation pressures $250 \mathrm{kPa}$ did not influence the operation and the maintenance of the cable cars.

Keywords: ice mechanics, foundation, bearing capacity, creep settlements

\section{Introduction}

Since the late sixties, alpine glaciers have been made accessible by cable cars, allowing for skiing in summer and giving people the opportunity to enjoy the high alpine scenery. In these early times of advancing glaciers the ice thickness was significantly higher than now. The surface velocities were up to $30 \mathrm{~m}$ per year at the Stubai glacier in Tyrol, Austria.

The first designers of cable car systems avoided the foundation of towers upon the glacier ice. The first T-bar lift with portal towers founded upon the ice was constructed in 1968 at the Hintertux Glacier in the Zillertal, Tyrol. The construction principle was based on fixing the tower heads by a holding rope, which was anchored in rock at the downhill and uphill station, whereas the tower footings were free to move with the glacier flow. For this reason the towers were connected with a hinge to the grate shaped footing. Several times per year, when the allowable displacement was reached, the footings were replaced in an uphill position, which was easy in those days due to the small and light towers.

Even though summer skiing is still not very popular, winter skiing on glaciers has increased in recent years due to the limited amount of snow in lower regions. Nowadays, the high season in glacier skiing regions starts in September and runs up to May. Therefore the capacity of single T-bar lifts was too low and sometimes two or more lifts were operating parallel to each other. Such a high amount of technical equipment obscures the view of the natural scenery.

Since 1995, T-bar lifts have been replaced by 6 person chair lifts with higher and heavier towers. For such constructions, a higher level in design was called for, e.g. a 
more precise survey of the glacier flow and higher safety requirements. Likewise the requirements for the foundation and replacing techniques increased.

The chair lifts, although fully functional, reached their transportation capacity at the end of the millennium. Hence 8 person gondola railways have been built since 2002, which brought again an increase in technical and safety requirements. Higher and heavier towers have been founded. To our knowledge, the highest tower is $20 \mathrm{~m}$ high with a weight of 37 tonnes.

Replacing the footing of such a large and heavy tower requires much more effort than replacing the footings of a light T-bar lift tower. The building of these large cable cars has been enabled because of the strongly retreating glaciers in the last twenty years, which has been accompanied by a drastic decrease in surface velocities, down to only 4 to 10 metres per year at Stubai glacier.

\section{Construction requirements}

Alpine glaciers creep downhill due to the gravity and the viscosity of ice, e.g. with surface velocities up to 3.5 metres per year (m/a) at the Theodul glacier in Switzerland [39] or 4 to $10 \mathrm{~m} / \mathrm{a}$ on the Stubai glacier in Tyrol, Austria [15].

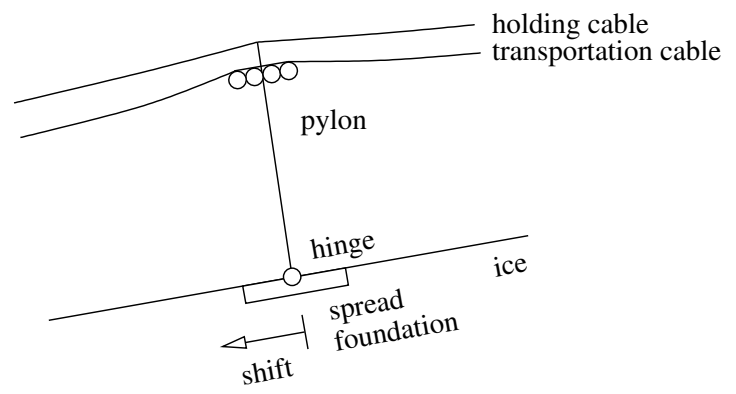

Abbildung 1: Schematic sketch of a tower foundation. It is designed to allow for a shift due to the glacier flow.

When towers of a cable car are founded directly on the ice surface, (i) the cable axis has to follow the flow line of the glacier, (ii) a hinge between the pylon and the spread foundation must allow for tilting in the cable car axis (Fig. 1) and (iii) each footing has 
to be replaced if the tilting becomes too large. Towers can only be placed in regions without crevasses, which has to be verified regularly. Due to asymmetric loading, the creep settlement can also cause lateral tilting. Therefore, the inclination of each tower in and perpendicular to the cable car axis has to be monitored continuously.

A light construction system is needed for easy and periodical replacement of the foundation, which is not too deeply founded in the ice. Very limited friction forces can be mobilised between foundation and ice and a minimum foundation depth is needed to sustain loads acting tangentially to the ice surface. To provide a form-locking connection with the ice, $\mathrm{u}$-shaped profiles are usually used, which are installed with the side walls downwards into the ice.

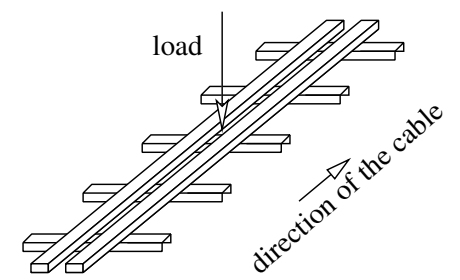

Abbildung 2: Schematic sketch of a typical footing system.

The spread foundations are constructed typically in the style of snow foundations [20], namely a series of u-shaped profiles perpendicular to the cable car axis connected with longitudinal beams, see Fig. 2. The length of the $\mathrm{u}$-shaped profiles and their spacing is typically large compared to the width of the profiles, thus each profile will be treated as a single strip foundation. Vertical nails could be used to enlarge the resistance against forces perpendicular to the cable car axis, however, it is better to weld transverse plates inside the u-shaped profile for ease of replacement. Clean ice is manually created as a surrounding for the footing.

\section{Ultimate limit state}

To verify the safety with respect to ultimate limit states of a tower foundation, the strength of glacier ice is required. 


\subsection{Strength of glacier ice}

Ice can deform by ductile creep or fail by brittle fracture, with a smooth transition between these two types of behaviour, depending on the strain rate. The ultimate load causes displacement or strain rates approaching infinity for ice exhibiting brittle response. We define therefore the strength of ice as the stress state that causes brittle failure, compare [34, Chapt. 4]. Stress states related with ductile creep are usually called yield stress, but should not be confused with the strength of ice.

The strength of ice can be described by a Coulomb relationship [36, 37, 38, 40], $\tau_{f}=c+\sigma_{n} \tan \varphi$, with the cohesion $c$, the friction angle $\varphi$ and $\sigma_{n}$ the normal stress acting upon the plane of the failure shear stress $\tau_{f}$.

The friction angle calculated from triaxial tests on iceberg ice at $-1{ }^{\circ} \mathrm{C}$, within a confining pressure range from $138 \mathrm{kPa}$ to $689 \mathrm{kPa}$ [9], is only $\varphi=4^{\circ}$. The friction angle of ice is decreasing with increasing temperature [8]. Thus it is expected that $\varphi$ is even lower for temperate glacier ice. Such low values are neglected in the following investigation. We will treat temperate glacier ice as purely cohesive material.

Ice behaves in a brittle fashion in unconfined uniaxial compression test for strain rates $\varepsilon>10^{-3} \mathrm{~s}^{-1}$, compare [34, Chapt. 4]. With $\varphi=0$ the cohesion can be determined from the peak stress: $c=\sigma_{\max } / 2$, with $\sigma_{\max }=\beta_{u}$, the so-called uniaxial compressive strength.

Unconfined uniaxial compression tests on ice from the Stubai glacier in Tyrol were performed with an adapted hydraulic point load apparatus at various temperatures [16]. The density of the specimens was $830<\varrho<890 \mathrm{~kg} / \mathrm{m}^{3}$, with $\varrho=860 \mathrm{~kg} / \mathrm{m}^{3}$ on average. The tests yield a sample mean value for the uniaxial compressive strength $\beta_{u}=1.3 \mathrm{MPa}$ at an air temperature in the testing chamber of slightly below $0^{\circ} \mathrm{C}$, and $\beta_{u}=2.1 \mathrm{MPa}$ at $-1.4^{\circ} \mathrm{C}$. The latter value compares well with $\beta_{u}=2.7 \mathrm{MPa}$ [19] gained with similar tests on clean Taylor glacier ice in Antarctica with an ice temperature of approximately $-4^{\circ} \mathrm{C}$ to $-1^{\circ} \mathrm{C}$. Field tests on typical lake and river ice in South Dakota give a mean value of $\beta_{u} \approx 3.3 \mathrm{MPa}[23]$ with unspecified temperatures in the field.

The coefficient of variation $V=\sigma / \mu$ of the uniaxial compressive strength of Stubai glacier ice is $28 \%$ for 22 specimens at $0^{\circ} \mathrm{C}$, and $37 \%$ for 44 specimens at $-1^{\circ} \mathrm{C}[16]$, 
where $\sigma$ is the standard deviation and $\mu$ the mean value. Unconfined compression tests on 5 specimens of an iceberg at $-1{ }^{\circ} \mathrm{C}$ showed a similar coefficient of variation, namely $22 \%$ [9]. Uniaxial compression tests on columnar ice at $-10^{\circ} \mathrm{C}$, collected in [21], show a coefficient of variation from $18 \%$ to $22 \%$.

In conclusion, the experiments with Stubai glacier ice are comparable with similar experiments on other glacier ice. Uniaxial compressive strength is minimal at melting temperature. This compressive strength is for Stubai glacier ice $\beta_{u}=1.3 \mathrm{MPa}$. All strength tests with ice show a significant scatter. In the following section we will therefore derive a cautious estimate of the strength with statistical methods.

\subsection{Ultimate bearing capacity}

\subsubsection{Mechanical model}

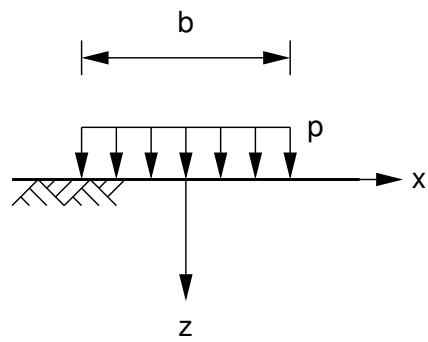

Abbildung 3: Pressure distribution of an infinite strip.

The bearing capacity is usually estimated with methods based on the slip-line field solution by Prandtl [32] in geotechnical engineering. It is also common to use these methods for a brittle material like rock [22, Chapt. 14.3] or frozen soil [7, 28]. The ultimate pressure $p_{u}$ between a centrally and vertically loaded strip foundation on a horizontal half space (Fig. 3) of purely cohesive material becomes:

$$
p_{u}=(2+\pi) c
$$

when using a failure criterion of the Tresca type, e.g. [34, Chapt. 6]. Tower foundations are usually made of several small strip foundations which are combined with longitudinal 
beams to a grating. The load acts mainly in the centre of the footing and perpendicular to the ground surface. Solutions for other footing geometries, eccentric loads, inclined loads and ground surface can be found, e.g. in [26].

\subsubsection{Characteristic value of the cohesion and partial safety factor}

In the ultimate limit state of typical geotechnical applications, slip lines or surfaces appear, which are rather large compared to the spatial variability of the soil. It is usually argued therefore that the mean value of the soil strength in the region of the slip line is decisive for the failure [12]. Thus the mean value of $c$ from strength tests is used as the characteristic value, e.g [4]. However, the tower foundations are small strip foundations (e.g. with a width of $b=30 \mathrm{~cm}$ ). The extension of the related failure mechanism is therefore small and an averaging of the strength values seems to be inappropriate. For this reason, the $5 \%$-fractile of the cohesion has been adopted as characteristic value.

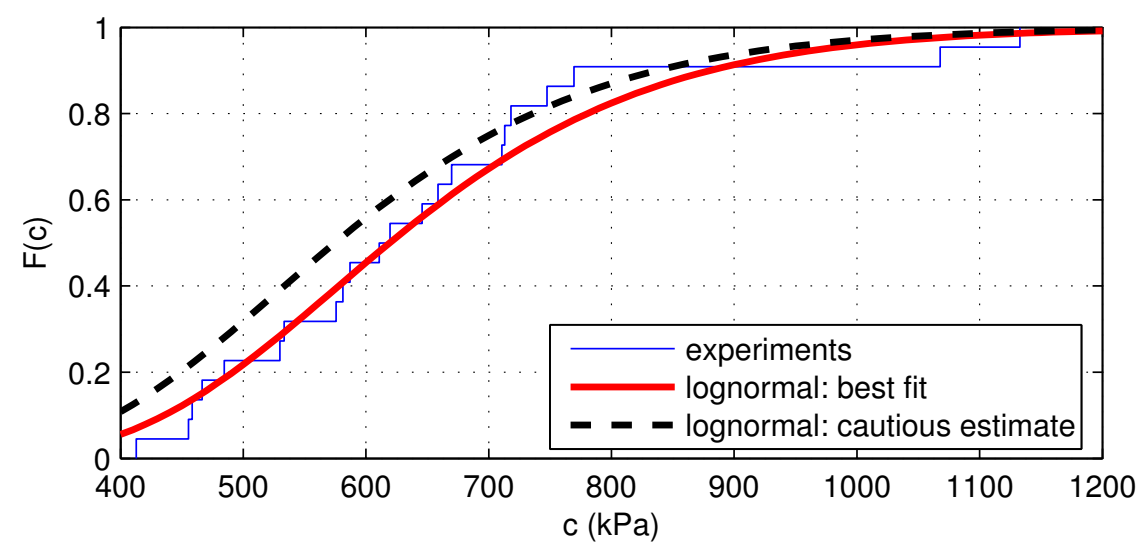

Abbildung 4: Cumulative distribution of the cohesion $c$ in rapid unconfined uniaxial tests with 22 specimens of glacier ice from Stubai in Tyrol at $0^{\circ} \mathrm{C}$, with an average density of $\varrho=860 \mathrm{~kg} / \mathrm{m}^{3}$. Parameters of the cumulative lognormal distributions: best fit $\mu_{c}^{\mathrm{opt}}=643 \mathrm{kPa}$ and $V_{c}^{\mathrm{opt}}=0.28$; cautious estimate $\mu_{c}=600 \mathrm{kPa}$ and $V_{c}=0.30$.

Since the cohesion cannot be negative, a lognormal distribution for $c$ has been assumed. 
The data in [16] can be fitted relatively well with this probability distribution with the parameters $\mu_{c}^{\mathrm{opt}}=643 \mathrm{kPa}$ and $V_{c}^{\mathrm{opt}}=0.28$, see Fig. 4 . With the cautious estimates $\mu_{c}=600 \mathrm{kPa}$ and $V_{c}=0.3$ and with the parameters of the lognormal distribution

$$
\mu_{\ln c}=\ln \frac{\mu_{c}}{\sqrt{1+V_{c}^{2}}} \quad, \quad \sigma_{\ln c}=\sqrt{\ln \left(1+V_{c}^{2}\right)},
$$

the characteristic value of the cohesion is:

$$
c_{k}=c_{5 \%}=\exp \left(\mu_{\ln c}-Q_{5 \%} \sigma_{\ln c}\right)=355 \mathrm{kPa},
$$

wherein $Q_{5 \%}=1.645$ is the $5 \%$-quantile of the standard normal distribution, e.g. [6]. The partial safety coefficient for a lognormally distributed resistance is

$$
\gamma_{c}=\exp \left(\alpha_{R} \beta V_{c}-Q_{5 \%} V_{c}\right)
$$

compare [5]. The reliability index is $\beta=4.7$ (brittle failure with serious consequences) for a reference period of one year [1]. The weighting factor reads $\alpha_{R}=0.8$ for the dominant resistance variable. With these values the partial safety factor for ice is

$$
\gamma_{c}=1.9
$$

if $c_{k}$ is set to the $5 \%$-fractile.

The design resistance pressure of a strip foundation on ice is

$$
p_{d}=(2+\pi) c_{d}=(2+\pi) \frac{c_{k}}{\gamma_{c}}=960 \mathrm{kPa}
$$

for temperate glacier ice with $\varrho>860 \mathrm{~kg} / \mathrm{m}^{3}$.

To compare this value with the old safety concept, we calculate the central safety factor $\eta=R_{k} / S_{k}$, with $R_{k}$ and $S_{k}$ being the characteristic values of the resistance and the load, respectively. The load on the cable car tower foundations is mainly a variable one, i.e. $\gamma_{S}=1.5$. The characteristic load not violating the limit condition can be called admissible foundation pressure for a vertical load

$$
S_{k}=p_{\mathrm{adm}}=p_{d} / \gamma_{s}=(2+\pi) \frac{c_{k}}{\gamma_{c} \gamma_{S}}=640 \mathrm{kPa}
$$


In geotechnical applications, the characteristic value of the resistance $R_{k}$ is calculated with the mean value of the strength, in our case

$$
R_{k}=(2+\pi) \mu_{c}
$$

The central safety factor to be applied is then, with (8) and (7)

$$
\eta=\frac{R_{k}}{S_{k}}=\gamma_{S} \gamma_{c} \frac{\mu_{c}}{c_{k}}=4.8
$$

In conclusion, the bearing capacity can be calculated based on results of uniaxial compression experiments. For a preliminary design according to the new eurocodes we propose to use a characteristic cohesion $c_{k}=355 \mathrm{kPa}$ and a partial safety factor $\gamma_{c}=1.9$ for pure glacier ice. A verification of these values by performing experiments with the ice in situ is necessary for the final design, especially when the foundation pressure is close to $p_{\text {adm }}=640 \mathrm{kPa}$.

\subsection{Safety against sliding}

Friction on ice at $0^{\circ} \mathrm{C}$ is very low, thus an $\mathrm{u}$-shaped profile is usually used as strip foundation. The simplified failure mechanism for such a profile caused by a horizontal load is shown in Fig. 5.

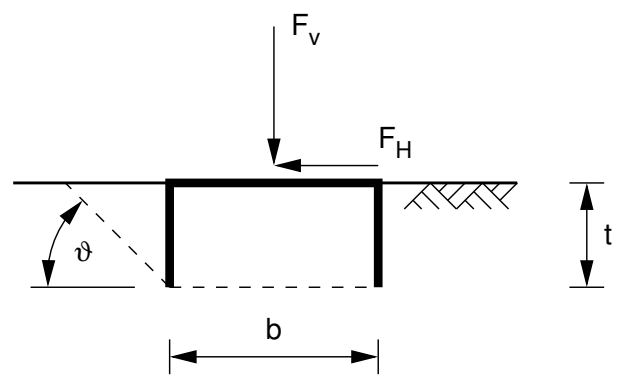

Abbildung 5: Failure mechanism for horizontal load.

For purely cohesive material, the angle of the slip line will be $\vartheta=45^{\circ}$, and the horizontal design resistance for a strip foundation with the length $\ell$ is:

$$
R_{H, d}=(b+t) \ell c_{d}
$$


with the design value of the cohesion $c_{d}=c_{k} / \gamma_{c}$. The limit condition must not be violated for the horizontal design load, i.e. $F_{H, d} \leq R_{H, d}$.

\section{Serviceability limit state}

\subsection{Elastic deformation}

It is well known that the elastic deformation is small compared to the creep deformation. For this reason, only the latter will be considered in the design.

\subsection{Creep of ice}

Keeping the actual load far below the bearing capacity, no cracks are expected to occur, thus the ice is in the so-called secondary creep range. There are several flow laws to model the secondary creep of ice, and there is no common fit to experimental data by different authors on different ice specimens, see an overview in [13, Chapt. 2]. Most popular are power relationships for unconfined uniaxial conditions, like Glen's flow law, which relates the uniaxial stress $\sigma$ with the uniaxial strain rate $\dot{\varepsilon}$ :

$$
\dot{\varepsilon}=A \sigma^{n},
$$

or polynomial expressions:

$$
\dot{\varepsilon}=\sum_{i=1}^{N} A_{i} \sigma^{n_{i}},
$$

with temperature dependent coefficients $A_{i}$.

A flow law will be required for temperate glacier ice, i.e. for ice at $0^{\circ} \mathrm{C}$, which is complicated because of limited data are available for this critical temperature. Four published fitted parameter sets are listed in Tab. 1. The uniaxial strain rates are plotted in Fig. 6 as functions of the uniaxial stress.

Due to the wide range of strain rates in Fig. 6, we can only expect to estimate the order of magnitude of the settlements. The relationship quoted by Nixon and McRoberts fits the experiments of Colbeck and Evans well for the stress range below $100 \mathrm{kPa}$ and those 


\begin{tabular}{|c|c|c|l|l|}
\hline$A_{i}\left(\mathrm{~s}^{-1} \mathrm{kPa}^{-n_{i}}\right)$ & $n_{i}$ & $T\left({ }^{\circ} \mathrm{C}\right)$ & source & authors \\
\hline$A=1.51 \times 10^{-15}$ & $n=3$ & $0^{\circ} \mathrm{C}$ & compiled data & Paterson $(2001)[27]$ \\
\hline$A=2.15 \times 10^{-17}$ & $n=3.2$ & $-0.02^{\circ} \mathrm{C}$ & $\begin{array}{l}\text { laboratory experiments } \\
90 \ldots 920 \mathrm{kPa}\end{array}$ & $\begin{array}{l}\text { Glen }(1955) \\
{[10]}\end{array}$ \\
\hline$A_{1}=2.38 \times 10^{-11}$ & $n_{1}=1.34$ & $0^{\circ} \mathrm{C}$ & $\begin{array}{l}\text { compiled data } \\
2 \ldots 140 \mathrm{kPa}\end{array}$ & $\begin{array}{l}\text { Nixon, McRoberts }(1976) \\
{[24]}\end{array}$ \\
$A_{2}=1.16 \times 10^{-17}$ & $n_{2}=4$ & & Colbeck, Evans $(1973)$ \\
$A_{1}=6.66 \times 10^{-11}$ & $n_{1}=1$ & $-0.01^{\circ} \mathrm{C}$ & field experiments \\
$A_{2}=4.44 \times 10^{-18}$ & $n_{2}=3$ & & $10 \ldots 100 \mathrm{kPa}$ & {$[3]$} \\
$A_{3}=9.02 \times 10^{-8}$ & $n_{2}=5$ & & $\varrho=890 \mathrm{~kg} / \mathrm{m}^{3}$ & \\
\hline
\end{tabular}

Tabelle 1: Parameters for Eqs. (11) and (12) for polycrystalline ice at $0^{\circ} ; \dot{\varepsilon}$ in $\mathrm{s}^{-1}$.

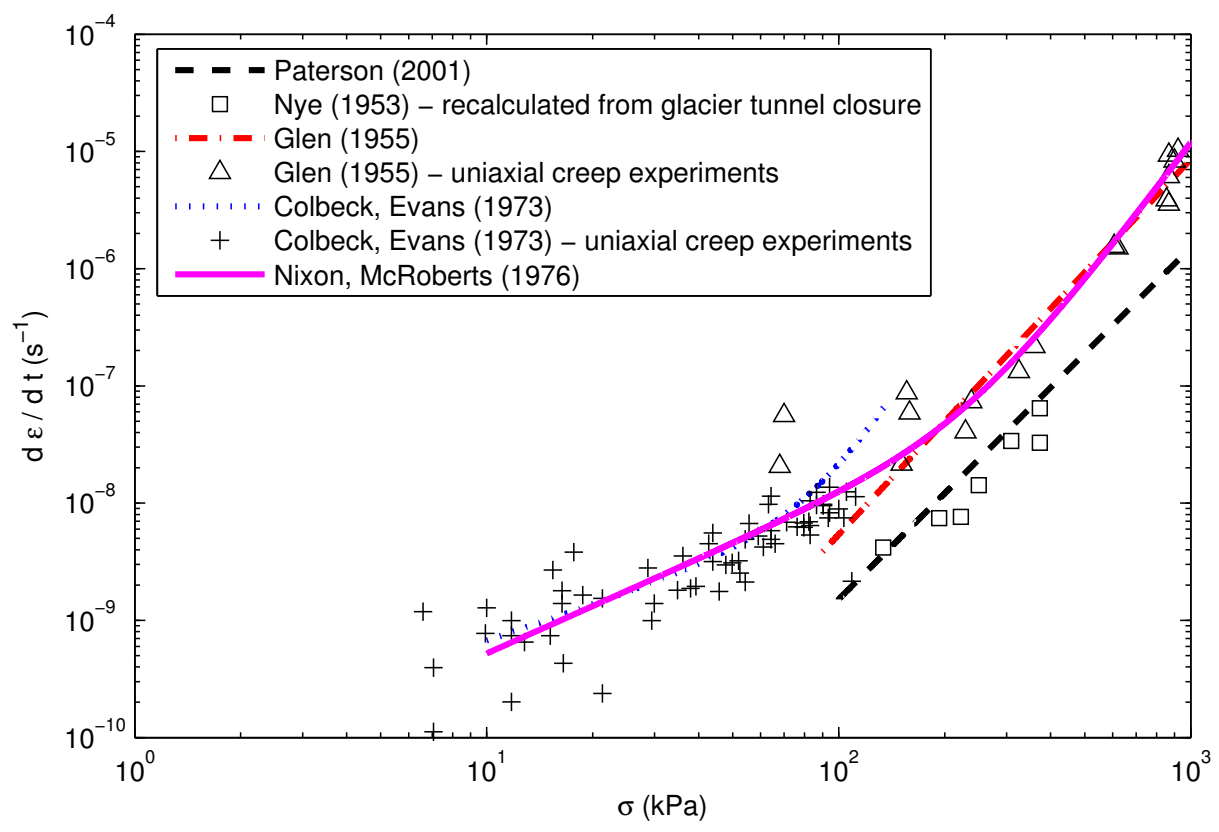

Abbildung 6: Creep of polycrystalline ice at $0^{\circ} \mathrm{C}$; lines denote published creep relationships with parameters from Tab. 1; symbols mark experimental results. 
of Glen for higher stresses. We will therefore choose the two-term polynomial relationship proposed by Nixon and McRoberts for our further studies.

The exponents $n_{i}$ of Nixon and McRoberts are similar to those published later by Gold [11]. In this work, low stress creep tests with temperatures less than $-10^{\circ} \mathrm{C}$ on columnar-grained ice have been fitted with $n_{1}=1$ and $n_{2}=4$.

\subsection{Rate of settlement}

The scatter of experimental results introduces uncertainties in assigning the material parameters of a specific formulation of the flow law. This will yield an uncertain computed settlement rate. This applies especially for a preliminary design, where no creep experiments with the local ice are available. In such situations, we propose the following approximate computation of the settlement rate.

\subsubsection{Mechanical model}

We can obtain an approximation of the settlement rate in the centre of a uniformly distributed surface load by using the stress field of the linear viscous problem and calculating the vertical strain rate using the non-linear flow law. This is the same idea as the standard settlement calculation in geotechnical engineering, where we use the stress field of the elastic problem with constant Young's modulus but calculate the local strain with a Young's modulus varying with depth, e.g. [14].

To calculate the stress field in the ice below the foundation, we use the similarity between linear elastic and linear viscous problems, which is briefly outlined in the following. The basis of any mechanical formulation of a quasi-static problem is the equilibrium equation $\operatorname{div} \boldsymbol{\sigma}=\varrho \mathbf{g}$, with the gravity $\mathbf{g}$ and the density $\varrho$. For an elastic material, the equilibrium equation is solved together with the constitutive relationship $\sigma=\mathbf{C}: \varepsilon$, with the fourth order elasticity tensor $\mathbf{C}$. In the case of a linear viscous material, the constitutive relationship reads $\boldsymbol{\sigma}=\mathbf{K}: \dot{\varepsilon}$, with the fourth order viscosity tensor $\mathbf{K}$. Mathematically, this means just replacing $\varepsilon$ with $\dot{\varepsilon}$ and $\mathbf{C}$ with $\mathbf{K}$ in the set of differential equations. In this sense, the elastic solution is equal to the linear viscous solution if the 
boundary conditions are equivalent, compare e.g. [33]. In particular, the stress field is the same in both cases, if $\mathbf{C}=\mathbf{K}$. The boundary conditions for the elastic and viscous problem are equivalent in the case of a strip foundation on an half space. Analytical solutions for the stress field of the elastic problem are available [30]. To account for the incompressible viscous flow of ice, the corresponding elastic stress field, which is equivalent to the linear viscous stress field, has to be calculated with a Poisson's ratio of $\nu=0.5$.

With the coordinate system in Fig. 3, the rate of settlement in the centre of the load is:

$$
\dot{u}=\int_{z=0}^{\infty} \dot{\varepsilon}_{z z}(z) \mathrm{d} z,
$$

with the strain rate $\dot{\varepsilon}_{z z}$ along the z-axis. Similar approaches were proposed in [24] for pile settlements in permafrost and in [31] for creeping soils. The latter approach was applied successfully for the prediction of creep settlements of embankments [35].

The one-dimensional flow law is generalised to calculate the strain rate for the threedimensional stress state. This is done using the assumption that ice is an incompressible non-linear viscous fluid, i.e. the hydrostatic stress does not influence the flow law [13]. Using the Mises equivalent stress

$$
\bar{q}=\sqrt{\frac{3}{2} s_{i j} s_{i j}},
$$

with the deviatoric stress

$$
s_{i j}=\sigma_{i j}-\frac{1}{3} \sigma_{i i} \delta_{i j},
$$

and the equivalent strain rate

$$
\dot{\bar{\varepsilon}}=\sqrt{\frac{2}{3} \dot{\varepsilon}_{i j} \dot{\varepsilon}_{i j}},
$$

we can formulate the flow law as

$$
\dot{\bar{\varepsilon}}=f(\bar{q}) .
$$


Each component of the strain-rate tensor can be expressed as

$$
\dot{\varepsilon}_{i j}=\frac{3}{2} \dot{\bar{\varepsilon}} \frac{s_{i j}}{\bar{q}}=\frac{3}{2} \frac{f(\bar{q})}{\bar{q}} s_{i j} .
$$

For example, the generalised Glen's flow law (11) reads

$$
\dot{\varepsilon}_{i j}=\frac{3}{2} A \bar{q}^{(n-1)} s_{i j}
$$

The generalised flow law of Nixon and McRoberts is

$$
\dot{\varepsilon}_{i j}=\frac{3}{2}\left(A_{1} \bar{q}^{\left(n_{1}-1\right)}+A_{2} \bar{q}^{\left(n_{2}-1\right)}\right) s_{i j} .
$$

The computation of the settlement rate is outlined in Fig. 7.

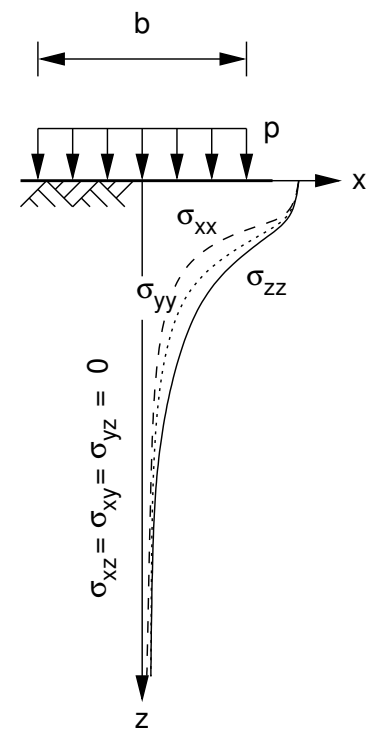

(a)

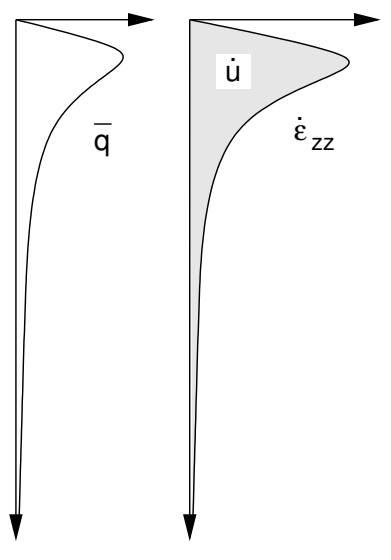

(b)

(c)

Abbildung 7: Computation of creep settlement: (a) calculation of the stress $\sigma_{i j}(z)$ below the centre of the load using elastic material properties $(\nu=0.5)$; (b) calculation of the Mises equivalent stress $\bar{q}$ with (14) based on the deviatoric stress $s_{i j}(z)$ from $(15) ;(\mathrm{c})$ calculation of the vertical strain rate $\dot{\varepsilon}_{z z}(z)$ with (20) and numerical integration over depth with (13) yields the settlement rate $\dot{u}$. 


\subsubsection{Comparison to indentation analysis}

The impressing of rigid indenters (Fig.8) into materials obeying Glen's law has been extensively studied aiming to predict the acting force for a given indentation rate.

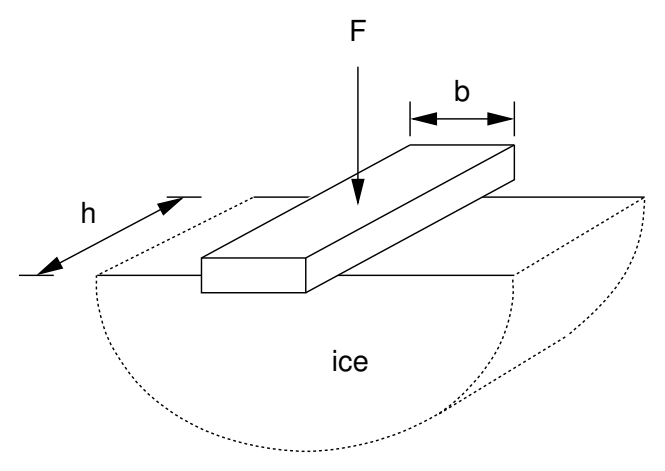

Abbildung 8: Edge indentation test.

The inversion of this problem can be used for a comparison with the approximate solution above outlined, assuming plane strain conditions for a strip foundation. The indentation rate $\dot{u}$ of a rigid indenter of the width $b$ into ice with an exponent $n=3$ can be written as $[18,29,34]$

$$
\dot{u}=\alpha b A p^{3} .
$$

For a rigid raft, the coefficient $\alpha$ can be calculated for plane strain conditions from [29] as $\alpha=5.0 \times 10^{-2}$, and from more recent work with fewer approximations [18] as $\alpha=6.7 \times 10^{-2}$. Horizontal forces have only a little effect on the vertical indentation rate [17] and can therefore be neglected. A numerical implementation of (13) and (20), with $n=3$ together with the elastic stress field of a distributed load on the surface of a semi-infinite space [30, Chapt. 3] with $\nu=0.5$ yields $\alpha=14.5 \times 10^{-2}$ in the investigated range $0.1<b<2 \mathrm{~m}$. In geotechnical engineering, it is common to multiply the settlement under a distributed load with a factor of $3 / 4$ to account roughly for the settlement reduction due to the rigidity of the raft [14]. If we apply the same factor here, we get $\alpha=10.9 \times 10^{-2}$, which is only slightly higher than the results of [18]. 


\subsubsection{Settlement rates for strip foundations}

The method outlined in Fig. 7 was used with the two term polynomial flow law (12) and the parameters of Nixon and McRoberts (3rd row in Tab. 1) in three dimensional expansion (18) to calculate the settlement rate of strip foundations on temperate glacier ice, see circles in Fig. 9.

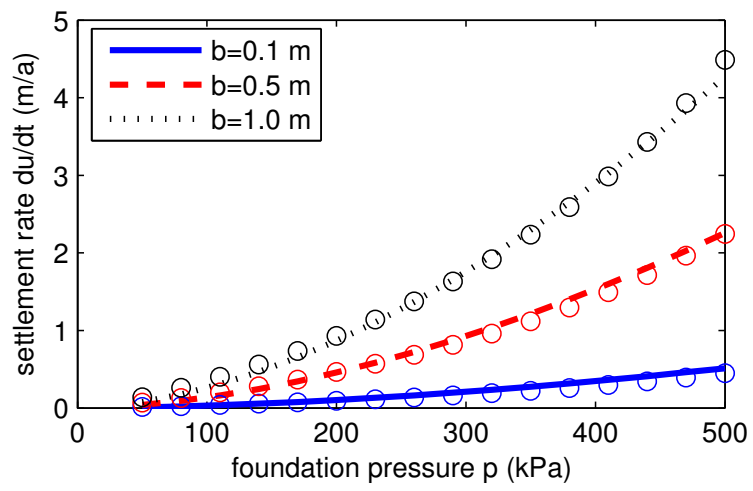

Abbildung 9: Settlement rate of strip foundations on temperate glacier ice: circles are values computed with the proposed approximate method; curves are calculated with Eq. (22).

The results can be fitted for pressures $50 \leq p \leq 500 \mathrm{kPa}$ and foundation widths $0.1 \leq b \leq 1 \mathrm{~m}$ (Fig. 9) by the expression

$$
\dot{u}=\beta_{1} b^{\beta_{2}} p^{\beta_{3}}
$$

with $\beta_{1}=8.6 \times 10^{-5} \mathrm{~m} \mathrm{kPa}^{-\beta_{3}} \mathrm{a}^{-1} \mathrm{~m}^{1-\beta_{2}}, \beta_{2}=0.92, \beta_{3}=1.74$. The dimensions of the variables in this equation are: $[b]=\mathrm{m},[p]=\mathrm{kPa}$ and $[\dot{u}]=\mathrm{m} / \mathrm{a}$. For an ice temperature of $-2^{\circ} \mathrm{C}$, the settlement rate decreases about an order of magnitude and the coefficients are $\beta_{1}\left(-2^{\circ} \mathrm{C}\right)=1.0 \times 10^{-6} \mathrm{~m} \mathrm{kPa}^{-\beta_{3}} \mathrm{a}^{-1} \mathrm{~m}^{1-\beta_{2}}, \beta_{2}\left(-2^{\circ} \mathrm{C}\right)=0.97, \beta_{3}\left(-2^{\circ} \mathrm{C}\right)=2.15$.

\subsubsection{Additional effects}

There are some additional effects causing settlements or changes of the level of the ice surface relative to the foundation. These are mainly 
- pressure melting below the foundation,

- melting due to heat transport from the tower to the foundation,

- ablation and accumulation.

Pressure melting: The constitutive model fits the experiments of Colbeck and Evans [3] quite well. These experiments were performed with various loads (10 to $100 \mathrm{kPa}$ ) on cuboid glacier ice samples tested directly in an ice tunnel. The air temperature next to the ice was about $0^{\circ} \mathrm{C}$. Such test conditions are highly comparable to the situation of a foundation on the surface of a glacier.

The shortening rate of a vertically loaded ice specimen due to pressure melting at top and bottom is independent of the height of the specimen. Dividing this shortening rate by the height will lead to a height dependence of the computed strain rate. Otherwise, the strain rate due to material creep does not depend on the sample height. The authors did not find a significant influence of the sample height on their computed flow law, thus they concluded that there has been almost no pressure melting in their experiments.

A theoretical approach to pressure melting [2] considers the indentation of a flat twodimensional body into an ice block at a temperature of $0^{\circ} \mathrm{C}$. The indentation speed solely due to pressure melting, $v$ in $\mathrm{m} / \mathrm{a}$ of a rigid strip foundation can be calculated as

$$
v=1.4 \times 10^{-4} \frac{p}{\sqrt{b}},
$$

with the pressure $p$ in $\mathrm{Pa}$ and the width of the foundation $b$ in $\mathrm{m}$. Moreover, the authors present a solution for the indentation of a circular disc. This relationship predicts the deformation rate due to pressure melting to be two orders of magnitude higher than the measured deformation rate in the experiments of Colbeck and Evans. Eq. (23) predicts an indentation rate of $v \approx 40 \mathrm{ma}^{-1}$ for a strip foundation with a width of $0.5 \mathrm{~m}$ when loaded with $p=200 \mathrm{kPa}$. Thus it is not recommended to use (23) for a settlement prediction of a foundation on glacier ice. Instead, the effects of pressure melting are assumed to be included already in the parameters of the flow law. 
Heat transfer: The heat transfer from the tower to the foundation is limited to the small cross section of the hinge construction. In addition, the ice and snow cover above the foundation (at least $0.5 \mathrm{~m}$ ) will absorb heat, and thus not all the heat will reach the ice below the foundation. There are only a few days with temperatures above $0^{\circ} \mathrm{C}$, e.g. at the meteorological station Jungfraujoch (Switzerland $3.580 \mathrm{~m}$ a.s.l) only 36 days per year on average have a positive daily average air temperature [39]. Thus, melting effects are assumed to be negligible compared to creep.

Ablation and accumulation: Those two effects can change the depth of the foundation. If the depth in an accumulation zone gets too high, the repositioning of the footing due to compensation of the glacier flow will be difficult. In any case, the hinge must never be covered by ice. Alternatively, the ice surface in the direct vicinity of the footing could drop below the foundation in the ablation zone, which will totally change the mechanical situation, i.e. this will imply a drastic reduction of the bearing capacity and an increase of the settlement rate. This scenario must be avoided in any case. Attention must be drawn to flowing water, which can also uncover the foundation by convection melting. If necessary, the area above and around the footing must be insulated with white foil or a snow heap to reduce ablation.

\section{Design charts}

The admissible bearing pressure of a strip foundation on temperate glacier ice is controlled by the ultimate bearing capacity and an admissible settlement rate. A design chart is provided through (22) for the serviceability limit state, Fig. 10. This figure shows the bearing pressures for various admissible settlement rates. All bearing pressures in this chart are well below the ultimate bearing capacity.

The designer of a foundation has to bear in mind that predicted settlement rates are rough estimates due to the uncertainty of the flow model. The construction should be insensitive to settlements. 


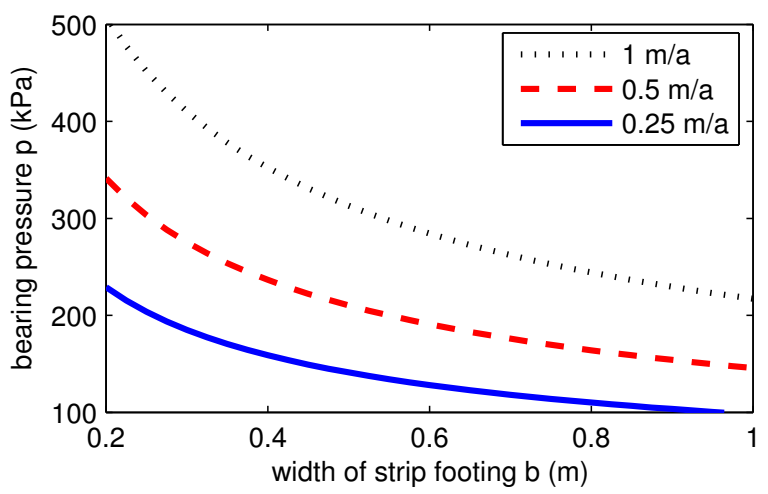

Abbildung 10: Bearing pressure for strip foundations on temperate glacier ice for various admissible settlement rates.

Example: We want to give a rough estimate of the settlements after one year operation for a strip foundation, with $b=20 \mathrm{~cm}$ and $p=500 \mathrm{kPa}$. The ice below the foundation will not have temperatures near zero degrees during the whole year. The surface will cool down in winter time and the settlement rates will be less than predicted for ice at zero degrees. Calculation with (13) showed that the predominant part of the deformations occurs within a depth of $3 b$ below the foundation. We assume for this example that the ice temperature is near $0^{\circ} \mathrm{C}$ for only half of the year. For the rest of the year, a settlement rate is assumed for an ice temperature of $-2^{\circ} \mathrm{C}$. The load $p=500 \mathrm{kPa}$ is composed by permanent (own weight) and variable (transported weight) actions. The variable part acts only during the operating time, which is assumed to be 10 hours per day. For our example we assume that half of the load is permanent. Thus the average settlement rate will be

$$
\begin{aligned}
\bar{u} & =\frac{1}{2}\left(\frac{10}{24} \dot{u}\left(500 \mathrm{kPa}, 0^{\circ}\right)+\frac{14}{24} \dot{u}\left(250 \mathrm{kPa}, 0^{\circ}\right)\right) \\
& +\frac{1}{2}\left(\frac{10}{24} \dot{u}\left(500 \mathrm{kPa},-2^{\circ}\right)+\frac{14}{24} \dot{u}\left(250 \mathrm{kPa},-2^{\circ}\right)\right)
\end{aligned}
$$

Applying (22) we estimate a settlement in one year of $u=40 \mathrm{~cm}$. This is less than the usually defined acceptable value of $1 \mathrm{~m}$ per year for such constructions [39]. However, field experiments are planned to verify this result. 


\section{Case studies}

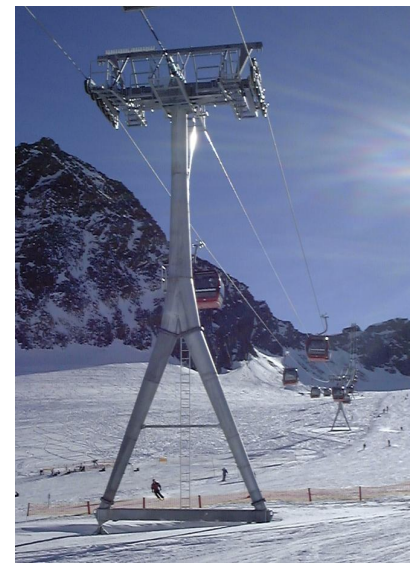

Abbildung 11: Gondola ropeway for 8 persons, Schaufeljoch, Stubai glacier.

Typical foundation pressures of two cable cars on Stubai glacier, which have been built in the years 1998 and 2003, are presented in Table 2. Both systems have Y-shaped towers (Fig. 11) each with two footings as shown schematically in Fig. 2. The total foundation area $A=2.25 \mathrm{~m}^{2}$ of each footing is composed of five u-shaped cross beams with the length $\ell=150 \mathrm{~cm}$ and the width $b=30 \mathrm{~cm}$. The height of the profiles is $t=10 \mathrm{~cm}$. The distance between the cross beams is $65 \mathrm{~cm}$.

\begin{tabular}{|l|c|c|c|c|}
\hline cable car & year & pylon height & $p_{\max }$ & $p_{G}$ \\
\hline Chair lift for 6 persons, Eisjoch & 1998 & $18 \mathrm{~m}$ & $184 \mathrm{kPa}$ & $90 \mathrm{kPa}$ \\
Gondola ropeway for 8 persons, Schaufeljoch & 2003 & $20 \mathrm{~m}$ & $250 \mathrm{kPa}$ & $145 \mathrm{kPa}$ \\
\hline
\end{tabular}

Tabelle 2: Cable cars on Stubai glacier: maximal foundation pressure $p_{\max }$ due to permanent plus variable loads, and the foundation pressure due to own weight $p_{G}$.

With the footing geometry above mentioned and the pressures given in Table 2, no problems concerning bearing capacity or settlements have arisen. The ablation on the Stubai glacier had not endangered the foundation. The yearly replacement of the footings 
of towers up to a weight of $370 \mathrm{kN}$ did not require excessive effort.

\section{Conclusion}

Cable cars towers can be founded directly on glacier ice. A method for design of such foundations is presented in this paper, which gives an admissible foundation pressure that is in agreement with cable cars that are already operating safely. The order of magnitude of creep settlements can be estimated. The yearly settlements of cable cars in operation do not influence the operation and the maintenance, e.g. the replacement of the foundations.

\section{Acknowledgement}

We thank the anonymous referees for valuable suggestions that helped to improve the paper.

\section{Literatur}

[1] ENV 1991-1: EUROCODE 1 PART 1. Basis of design and actions on structures Basis of design. European Committee for Standardization, 1994.

[2] A. Bejan and P.A. Tyvand. The pressure melting of ice under a body with flat base. Journal of Heat Transfer, 114:529-531, 1992.

[3] S.C. Colbeck and R.J. Evans. A flow law for temperate glacier ice. Journal of Glaciology, 12(4):71-86, 1973.

[4] W. Fellin. Assessment of characteristic shear strength parameters of soil and its implication in geotechnical design. In W. Fellin, H. Lessmann, M. Oberguggenberger, and R. Vieider, editors, Analyzing Uncertainty in Civil Engineering, pages 1-15. Springer, Berlin Heidlberg, 2004. 
[5] L. Fischer. Sicherheitskonzept für neue Normen - ENV und DIN-neu, Teil 10. Bautechnik, 76(11):1015-1023, 1999.

[6] L. Fischer. Sicherheitskonzept für neue Normen - ENV und DIN-neu, Teil 3. Bautechnik, 76(3):236-253, 1999.

[7] A.M. Fish. Comparison of U.S.S.R. codes and U.S. Army manual for design of foundations on permafrost. Cold Regions Science and Technology, 8:3-24, 1983.

[8] A.M. Fish and Y.K. Zaretsky. Ice strength as a function of hydrostatic pressure and temperature. Technical Report 97-6, US Army Corps of Engineers, Cold Regions Research \& Engineering Laboratory, New Hmpshire, USA, 1997.

[9] R.E. Gagnon and P.H. Gammon. Triaxial experiments on iceberg and glacier ice. Journal of Glaciology, 41(139):528-540, 1995.

[10] J.W. Glen. The creep of polycrystalline ice. Proceedings of the Royal Society London, Series A, 228(1175):519-538, 1955.

[11] L.W. Gold. Creep of columnar-grained ice at low stress. Annals of Glaciology, 4:73-78, 1983.

[12] G. Gudehus. Sicherheitsnachweise für Grundbauwerke. Geotechnik, 10(1):4-34, 1987.

[13] K. Hutter. Theoretical Glaciology. Kluwer, Dordrecht, 1983.

[14] D. Kolymbas. Geotechnik - Bodenmechanik und Grundbau. Springer, Berlin Heidlberg, 1998.

[15] B. Lackinger. Eismechanisches und geotechnisches Gutachten - Eisjoch / Stubaier Gletscher. Internal expertise for Stubaier Bergbahnen KG, 1998.

[16] M. Lair. Festigkeit von Eis. Master's thesis, Universität Innsbruck, Austria, 2004.

[17] J. Larsson and B. Storåkers. Oblique indentation of creeping solid. European Journal of Mechanics - A/Solids, 19:565-584, 2000. 
[18] P.L. Larsson. On creep deformation at plane contact problems. Cold Regions Science and Technology, 26:67-82, 1997.

[19] W. Lawson. The relative strengths of debris-laden basal ice and clean glacier ice: some evidence from Taylor Glacier, Antartica. Annals of Glaciology, 23:270-276, 1999.

[20] M. Mellor. Foundations and subsurface structures in snow. Cold Regions Research and Engineering Laboratoy (CRREL), Monograph III-A2c, New Hmpshire, USA, 1969.

[21] B. Michel and N. Toussant. Mechanisms and theory of indentation of ice plates. Journal of Glaciology, 19(81):285-300, 1977.

[22] L. Müller. Der Felsbau. Enke Ferdinand, Stuttgart, 1992.

[23] C.A Niehus. Evaluation of factors affecting ice forces at selected bridges in South Dakota. Water-Resources Investigations Report 02-4158. U.S. Department of the Interior, U.S. Geological Survey, Denver, 2002.

[24] J.F. Nixon and E.C. McRoberts. A design approach for pile foundations in permafrost. Canadian Geotechnical Journal, 13(40), 1976.

[25] J.F. Nye. The flow law of ice from measurements in glacier tunnels laboratory experiments and the Jungfraufirn borehole experiment. Proceedings of the Royal Society London, Series A, 219(1139):477-489, 1953.

[26] ÖNORM B4435-2. Erd- und Grundbau, Flächengründungen, EUROCODE-nahe Berechnung der Tragfähigkeit. Östereichisches Normungsinstitut, Wien, 1999.

[27] W.S.B. Paterson. The physics of glaciers. Butterworth - Heinemann, Oxford, 3 edition, 2001.

[28] A. Phukan. Foundation in cold regions. In H.Y. Fang, editor, Foundation Engineering Handbook, pages 735-749. Chapman \& Hall, New York, 1991. 
[29] A.R.S. Ponter, A.C. Palmer, D.J. Goodman, M.F. Ashby, A.G. Evans, and J.W. Hutchinson. The force exerted by a moving ice sheet on an offshore structure. Cold Regions Science and Technology, 8:109-118, 1983.

[30] H.G. Poulos and E.H. Davis. Elastic solutions for soil and rock mechanics. Series in soil engineering. Wiley, New York, 1974.

[31] H.G. Poulos, L.P. de Ambrosis, and E.H. Davis. Method of calculating long-term creep settlements. Journal of the Geotechnical Engineering Division, 102(102):787804, 1976.

[32] L. Prandtl. Über die Härte plastischer Körper. Nachrichten von der Königlichen Gesellschaft der Wissenschaften zu Göttingen, pages 74-85, 1920.

[33] B. Salm. Snow forces. Journal of Glaciology, 19(81):67-100, 1977.

[34] T.J.O. Sanderson. Ice Mechanics: Risk to Offshore Structures. Graham \& Trotman, London, 1988.

[35] W. Schober and A. Sint. Kriechverformung feinkörniger Böden. Number 230 in Straßenforschung. Bundesministerium für Bauten und Technik, Wien, 1983.

[36] E.M. Schulson. Brittle failure of ice. Engineering Fracture Mechanics, 68:1839-1887, 2001.

[37] E.M. Schulson. Compressive shear faults in ice: plastic vs. Coulombic faults. Acta Materialia, 50:3415-3424, 2002.

[38] E.M. Schulson and E.T. Gratz. The brittle compressive failure of orthotropic ice under triaxial loading. Acta Materialia, 47(3):745-755, 1998.

[39] S. Suter and M. Funk. Eismechanisches Gutachten für den Oberen Theodulgletscher. Technical Report 7943.52.04, Versuchsanstalt für Wasserbau, Hydrologie und Glaziologie, ETH Zürich, 2002. 
[40] J. Weiss and Schulson E.M. The failure of fresh-water granular ice under multi-axial compressive loading. Acta Metallurgica et Materialia, 43(6):2303-2315, 1995. 